Journal of Fisheries and Aquatic Science 9 (2): 63-74, 2014

ISSN 1816-4927 / DOI: 10.3923/jfas.2014.63.74

(C) 2014 Academic Journals Inc.

\title{
Histological Changes of Liver in Overfed Young Nile Tilapia
}

\author{
${ }^{1,2}$ Fasil Taddese, ${ }^{1}$ M.D. Huh, ${ }^{3}$ Sungchul C. Bai and ${ }^{4}$ J. Vijverberg \\ ${ }^{1}$ Department of Aquatic Life Medicine, Pukyong National University, 599-1, Daeyeon 3-Dong, Busan, \\ 608-737, Republic of Korea \\ ${ }^{2}$ Fisheries, Wetlands and Wildlife Management Program, Bahir Dar University, P.O. Box 1901, Bahir Dar, \\ Ethiopia \\ ${ }^{3}$ Department of Marine Bio-Materials and Aquaculture, Pukyong National University, 599-1 Daeyeon \\ 3-Dong, Busan, 608-737, Republic of Korea, Korea \\ ${ }^{4}$ Netherlands Institute of Ecology (NIOO-KNAW), Droevendaalsesteeg 10, 6708 PB, Wageningen, \\ Netherlands
}

Corresponding Author: Fasil Taddese, Department of Aquatic Life Medicine, Pukyong National University, 599-1, Daeyeon 3-Dong, Busan, 608-737, Republic of Korea, Korea Tel: +251-924-516049

\begin{abstract}
We investigated histopathologically liver structural responses of Nile Tilapia Oreochromis niloticus towards overfeeding. Mixed population of $O$. niloticus with mean weight of $55 \pm 3.83 \mathrm{~g}$ was acclimated for one week. Then, the fish were separated into control and treatment groups. Glass aquariums with external biofilters and artificial heaters were used. Control and treatment groups were fed commercial Tilapia diet at 3 and $6 \%$ of fish body weight, respectively. Fish were dissected at three time intervals. Tissues were fixed, re-fixed, processed, embedded with paraffin and sectioned. Sectioned tissue ribbons were stained with hematoxylin and eosin technique for light microcopy. Hepatosomatic Index (HSI) and Hepatohypertrophic Index (HHI) were calculated. Irregular shaped hepatocytes with circular, conspicuous and centrally located nuclei were found from all control groups. Large hypertrophic hepatocytes with nuclei dislocated to the cell periphery observed after three weeks of overfeeding. Lipid vacuolation and atrophy were found after five weeks of overfeeding. Fish overfed for three weeks showed significantly $(p<0.05)$ higher HSI and HHI values. Whereas, fish which were under third week control group showed the second significantly $(p<0.05)$ higher HSI value. Significant $(p<0.05)$ differences in HSI as well as HHI were not found between zero and fifth week control groups. We conclude that overfeeding may cause liver histological alterations in $O$. niloticus and in turn lower aquaculture profitability by making the fish susceptible to disease.
\end{abstract}

Key words: Feeding level, hepatocyte, morphology, alteration

\section{INTRODUCTION}

In fish culture operations feed and feeding accounts for the highest cost. Optimum feeding is one of the ways through which cost is minimized as well as better growth is achieved. However, the traditional management strategy for maximizing growth is by maximizing feeding (Gao and Lee, 2012). Besides, feeding regimes are known to be one of the most disputed areas in Tilapia nutrition (El-Sayed, 2006). Various feeding regimes are in use for tilapia depending on culture conditions and nutritional composition of the feed. Feeding levels ranging from 2\% (El-Saidy and 
Gaber, 2005) up to 5\% (Boyd, 2004) of fish body weight are recommended as optimum. Therefore, a better insight in the effects of overfeeding in fish is urgently needed.

The alimentary canal of teleostean fishes has been widely studied and described morphologically to determine the function of many specialized anatomical structures in relation to the different feeding adaptation of this large group (Cataldi et al., 1987). Liver is the major organ in the digestive system of fish. The teleost liver is relatively large dense organ ventrally located in the cranial region of the general cavity (Jobling, 2012). Its size, shape and volume are adapted to the space available between other visceral organs (Vicentini et al., 2005). In wild fish it is usually reddish brown in carnivores and light brown in herbivores but at certain times of year it may be yellow. In farmed fishes, where diets generally contain higher levels of lipids, it is usually lighter in color than in the equivalent wild specimen.

Fish liver serves functions similar to those in mammals. Its functions include assimilation of nutrients, production of bile, detoxification and maintenance of the body metabolic homeostasis that includes processing of carbohydrates, proteins, lipids and vitamins (Genten et al., 2009; Jobling, 2012). Liver also plays a key role in the synthesis of plasma proteins, like albumin, fibrinogen and complement factors.

The microstructure of the liver varies among species, but there are general traits in majority of species (Ferguson, 2006). The liver of the O. niloticus is a large organ and has only two lobes (Vicentini et al., 2005); the left lobe is bigger than the right lobe and spreads throughout almost the entire corporeal cavity. Nutritional and physiological status of many fishes has been studied by using liver as an indicator. Various authors have described the effects of different nutritional conditions on liver. Caballero et al. (1999) studied the effect of lipid level and fish meal quality on liver of gilthead sea bream and found swelling hepatocytes. The effect of different lipid sources on liver of Pangasius nasutus was observed by Asdari et al. (2011). Histological methods in the assessment of different feed effects on liver and intestine of fish were reviewed and explained by Raskovic et al. (2011).

Many authors explained fish liver alterations as a result of toxic substances e.g., zinc (Abdel-Warith et al., 2011), aluminum (Hadi and Alwan, 2012), cadmium sulphate (Jalaludeen et al., 2012) and trichlorofon ( $\mathrm{Xu}$ et al., 2012). Effects of various substances such as ethanolic extracts of Ipomoea aquatica leaf (Oluwatoyin, 2011) and toxic Cyanobacterium Microcystis aeruginosa (Fahprathanchai et al., 2007) on fish liver were also reported.

The majority of the researches on histopathology of fishes have focused on the quality of the feed as a cause for liver alterations and not on the quantity. Up till now, most researches consider water quality deterioration (Masser et al., 1992; Mohanty, 2001) and higher costs of production to be the main consequences of overfeeding.

Only few researchers have reported histological changes of the liver as response to overfeeding. Phillips and Podoliak (1957) indicated that excessive fat deposition in trout's liver as well as kidney is caused by overfeeding. Storch et al. (1983) observed that feeding level can provoke alteration of hepatocytes in milkfish fry. Verreth et al. (1994) also mentioned that feeding level can cause an accumulation of lipid in the liver of Clarias gariepinus. According to these authors, feeding level is the most decisive parameter for larval growth and metabolic performance of the liver.

So far, only little attention was given to overfeeding as a direct stressor to the fish liver. Thus, clear and detailed information about the effect of overfeeding on morphological alterations of liver is lacking. Specifically, studies which show how the liver of $O$. niloticus responds to increased 
feeding level are scarce. The present study aimed to fill this gap. The main objective of this study is to investigate liver histological alterations of the Nile Tilapia, O. niloticus in response to overfeeding.

\section{MATERIALS AND METHODS}

The research was carried out at Laboratory of Fish and Shellfish Pathology (LFSP) Pukyong National University, Korea. Mixed sex population of Nile Tilapia, with mean weight of $55 \pm 3.83 \mathrm{~g}$, were obtained from freshwater fish farm of the University. Twelve randomly selected fishes were scarified before the beginning of feeding trial. The rest of the 52 fishes were acclimated to the experimental condition for about one week after arrival.

Fish were fed commercial tilapia diet with 38\% Crude Protein and 6\% Crude Fat content. The feed was purchased from Woosung Feed Co. Ltd., Korea. Composition of the diet (Table 1) was given by the company. After acclimation the fish distributed equally and randomly to four $170 \mathrm{~L}$ aquariums categorized into two groups, treatment and control. Each group was duplicated.

External biofilters (PhilGreen model Ef-1300, China) were used to recycle the water. Water temperature was maintained at $27 \pm 1^{\circ} \mathrm{C}$. Dissolved oxygen was $6-7 \mathrm{mg} \mathrm{L} \mathrm{L}^{-1}$ and $\mathrm{pH}$ was within the range of 7.2-7.5. Ammonia level was kept below $1 \mathrm{mg} \mathrm{L}^{-1}$. All optimum water quality requirements for O. niloticus were maintained (El-Sayed, 2006) and a photoperiod of $12 \mathrm{D}$ and $12 \mathrm{~L}$ h were kept. Regular cleaning of biofilters were done to prevent clogging and to maintain filtering efficiency.

Feeding: Feed was provided constantly as a percentage of fish body weight. The fish in the treatment group were fed four times per day at 09:00, 12:00, 15:00 and 18:00 h 6\% of their body weight. The feed was weighed and divided into four parts equally. While those fish in the control category were fed two times per day $3 \%$ of their body weight at 09:00 and 18:00 h in the same manner. The treatment feeding level was set by defining overfeeding as feeding beyond the optimum or standard feeding level.

The fish in the treatment group were fed more frequently than the control ones to maximize their appetite. In frequent feedings each subsequent meal is known to increase the stomach volume (Riche et al., 2004) and the rate of evacuation is assumed to be faster when the stomach volume increases. Then, each evacuation brings appetite back and let the fish eat more. Feeding level adjustment was made for both control and treatment groups every two weeks in accordance with their body weight gain.

Histological analysis: Benzocaine was used at a concentration of $50 \mathrm{mg} \mathrm{L}^{-1}$ (Coyle et al., 2004) to euthanize the fish before dissection. Fish were dissected before the beginning of feeding, at third week and at fifth week periods. Images of internal organs were taken using digital camera (Olympus E-P2 Japan) during dissection. After gross examination of the other internal organs, whole livers of each fish were carefully removed from the body and weighed. A part of liver tissue was dissected and pre-fixed in Bouin's fixative solution. Following post-fixation the liver tissue blocks were washed with tap water and then dehydrated in graded series of 70 100\% alcohol. After cleaning and paraffin embedding, tissue slices of $5 \mu \mathrm{m}$ thickness were obtained using rotary type microtome (Reichert Jung 820, Leica, Germany). Liver tissues were stained with Hematoxylin and Eosin ( $\mathrm{H}$ and $\mathrm{E}$ ) for histological examination with a light microscope (U-MDOB, Olympus optical Co. Ltd., Japan). Images of the prepared slides were taken by using the software DP2-BSW (Olympus, Japan). 
As indication for the liver condition two different indices were calculated.

The Hepatosomatic Index (HSI) was determined (Htun-Han, 1978) as:

$$
\text { Hepatosomatic index }(\mathrm{HSI})=\frac{\text { Liver weight }(\mathrm{g})}{\text { Body weight }(\mathrm{g})} \times 100
$$

The Hepatohypertrophic Index (HHI) was calculated using the following equation (Lee, 2008):

$$
\text { Hepatohypertrophic index }(\mathrm{HHI})=\frac{1}{\log (\mathrm{n})}
$$

Where:

$\mathrm{n}=$ No. of nuclei in $1000 \mu \mathrm{m}^{2}$ of hepatic tissue

Data analysis: Histopathological description of morphological alterations and statistical analysis of indices were used to present the research findings. Comparisons were made between controls and treatments as well as between different weeks' results. One way ANOVA and Duncan`s multiple range test (Duncan, 1955) were used on SPSS version 16 (SPSS Inc. Chicago, USA) to detect the significant differences among all groups.

\section{RESULTS}

Gross liver observation: Almost all of fish livers during the first dissection, before the start of feeding experiment, appeared to be normal (Fig. 1a). No external abnormality was observed. Similar normal livers with brown color were observed from fish fed at their optimum requirement during the third and fifth week (Fig. 1 b and 2).
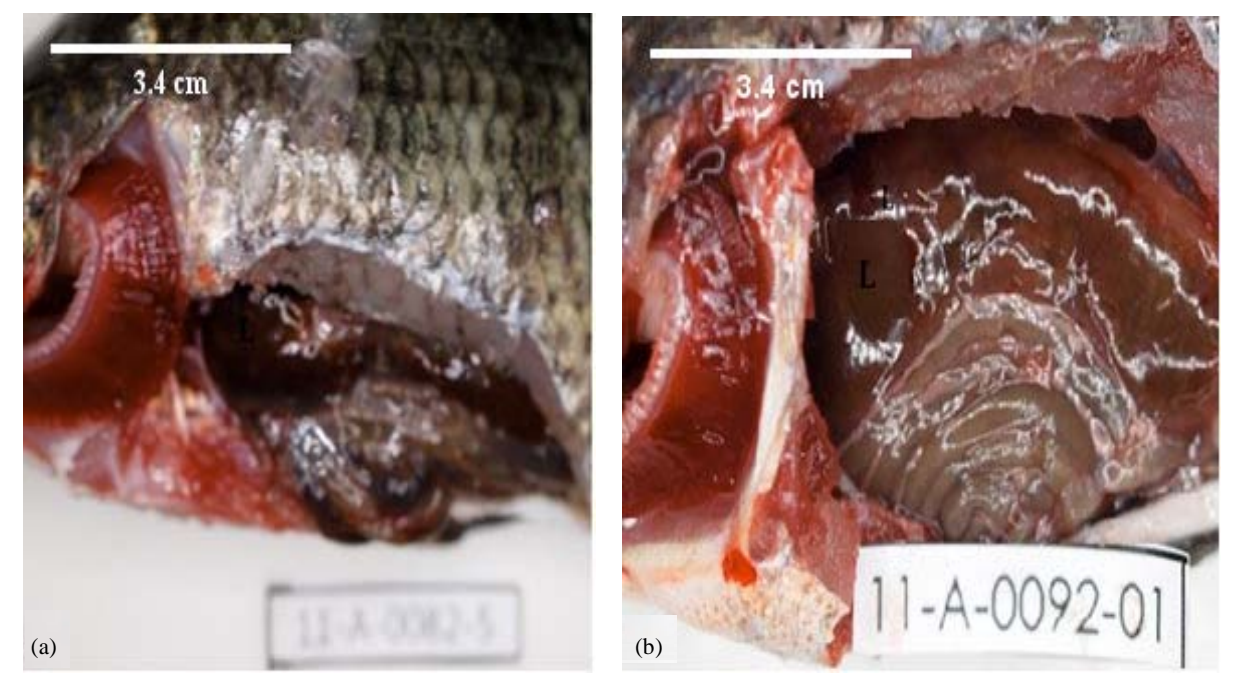

Fig. 1(a-b): Gross appearance of liver from control groups. (a) Before the beginning of feeding and (b) Optimum feeding week three, Olympus, Japan; L-liver. Scale bar-3.4 cm 


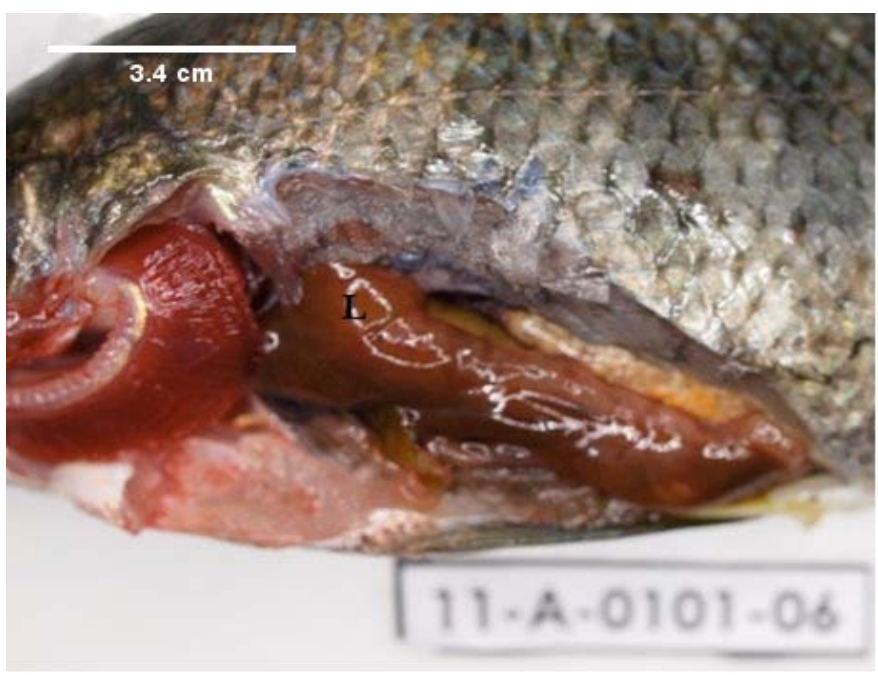

Fig. 2: Gross appearance of liver from fifth week control, Olympus, Japan; L-liver. Scale bar $-3.4 \mathrm{~cm}$
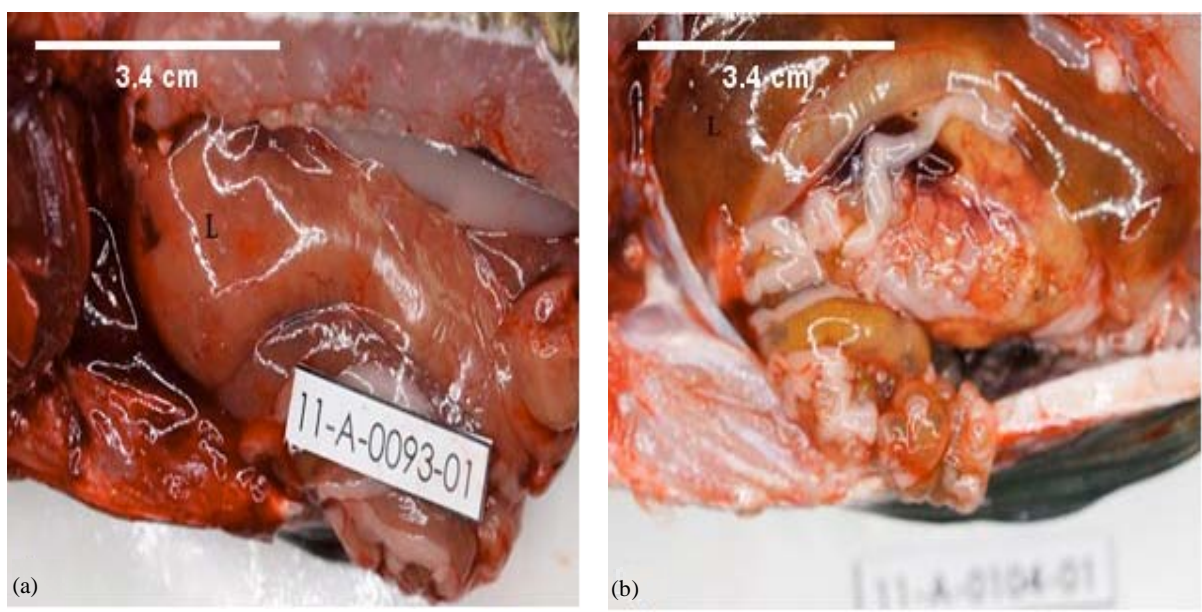

Fig. 3(a-b): Gross appearance of liver after overfeeding. (a) After three weeks of overfeeding and (b) After five weeks of overfeeding. Olympus, Japan; L -liver. Scale bar-3.4 cm

Whereas, after three weeks of overfeeding relatively large sized livers with pale brown color (Fig. 3a) were found. Shiny and oily livers were also seen during week three in overfed fish. Those abnormalities occurred after three weeks of overfeeding and were also observed after five weeks (Fig. 3b). The only difference was that in the fifth week the frequency of pale and oily appearances were higher than in the third week.

Microscopic liver observation: Normal irregular shaped hepatocytes with very prominent circular nuclei (Fig. 4a and b) were found in fish which were dissected before the start of the experiment. The same kinds of healthy hepatocytes with conspicuous centrally located circular nuclei were found in fish which were under optimum feeding regime during both the third 
J. Fish. Aquat. Sci., 9 (2): 63-74, 2014
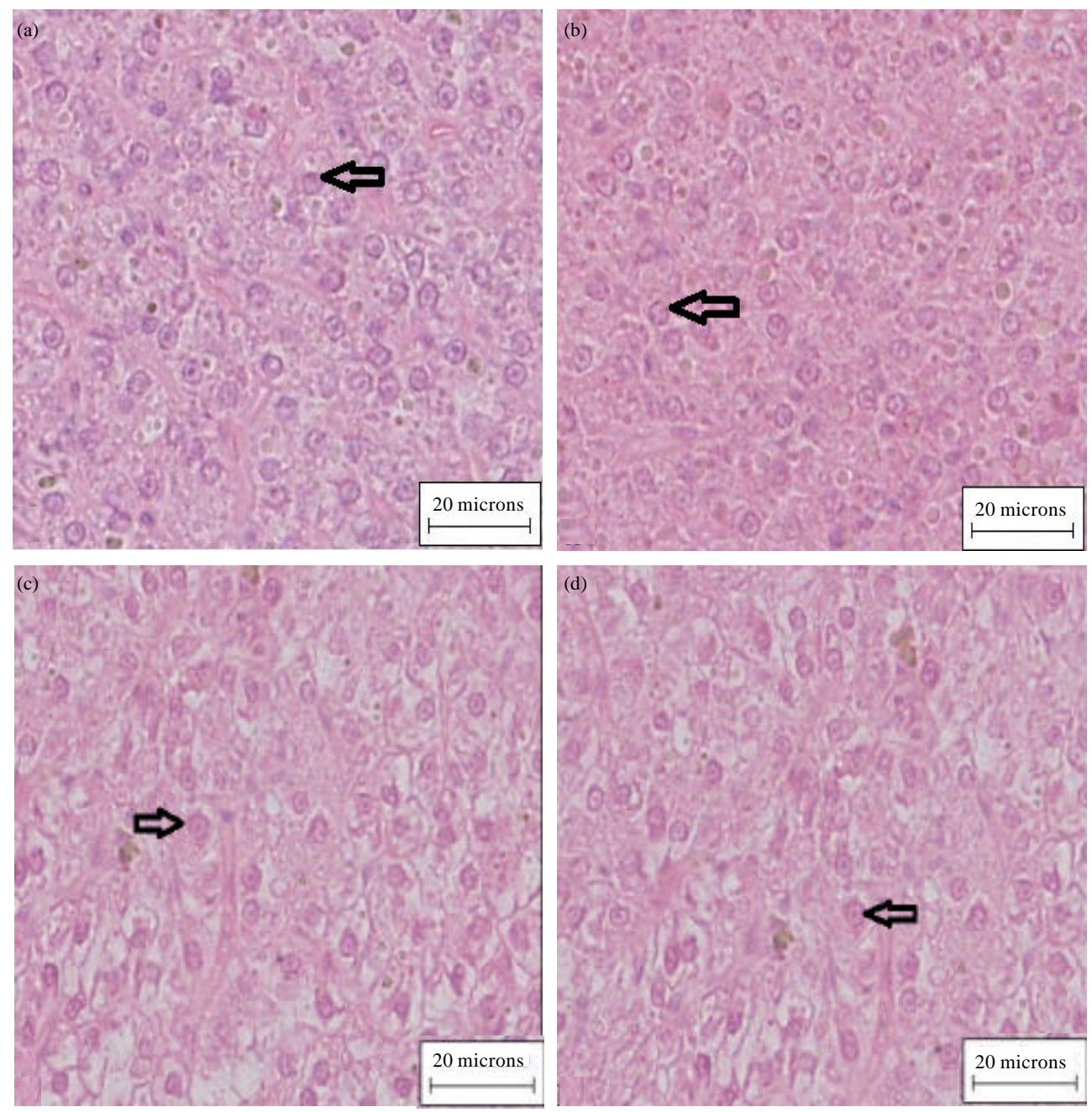

Fig. 4(a-d): (a and b) Liver microscopic structure before the beginning of feeding trial and (c and d) After three weeks of optimum feeding. Normal hepatocytes with conspicuous, circular and centrally located nuclei (arrows) (H and E; X400; Scale bars $20 \mu \mathrm{m}$ )

Table 1: Nutritional composition of the feed (according to Woosung Feed Co. Ltd., Korea)

\begin{tabular}{llllll}
\hline Crude protein (\%) & Crude fat (\%) & Crude fiber (\%) & Crude Ash (\%) & $\mathrm{P} \mathrm{( \% )}$ & Ca (\%) \\
\hline 38 & 6 & 18 & 6 & 0.8 & 1.8 \\
\hline
\end{tabular}

Table 2: Mean $\pm \mathrm{SE}$ of hepatosomatic index ( $<<0.05$ ); mean values with different letters are significantly different

\begin{tabular}{lcc}
\hline Feeding group & N & Hepatosomatic index (HSI) \\
\hline Control week zero & 12 & $1.04 \pm 0.06^{\mathrm{d}}$ \\
Control week three & 9 & $1.95 \pm 0.12^{\mathrm{b}}$ \\
Treatment week three & 9 & $3.07 \pm 0.24^{\mathrm{a}}$ \\
Control week five & 17 & $1.11 \pm 0.08^{\mathrm{d}}$ \\
Treatment week five & 16 & $1.52 \pm 0.10^{\mathrm{c}}$ \\
\hline
\end{tabular}

(Fig. 4c and d) and the fifth week (Fig. 5a and b). Very few hepatocyte hypertrophy incidents were found after three weeks of optimum feeding (Table 2). 

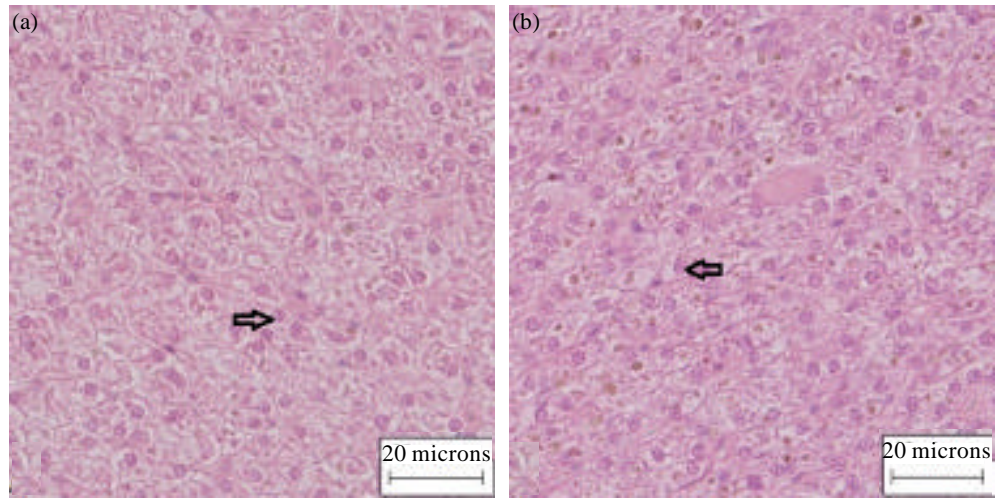

Fig. 5(a-b): Liver microscopic structure after five weeks of optimum feeding (a and b) Normal hepatocytes with circular conspicuous and centrally located nuclei (arrows) (H and E; X400; Scale bars: $-20 \mu \mathrm{m})$
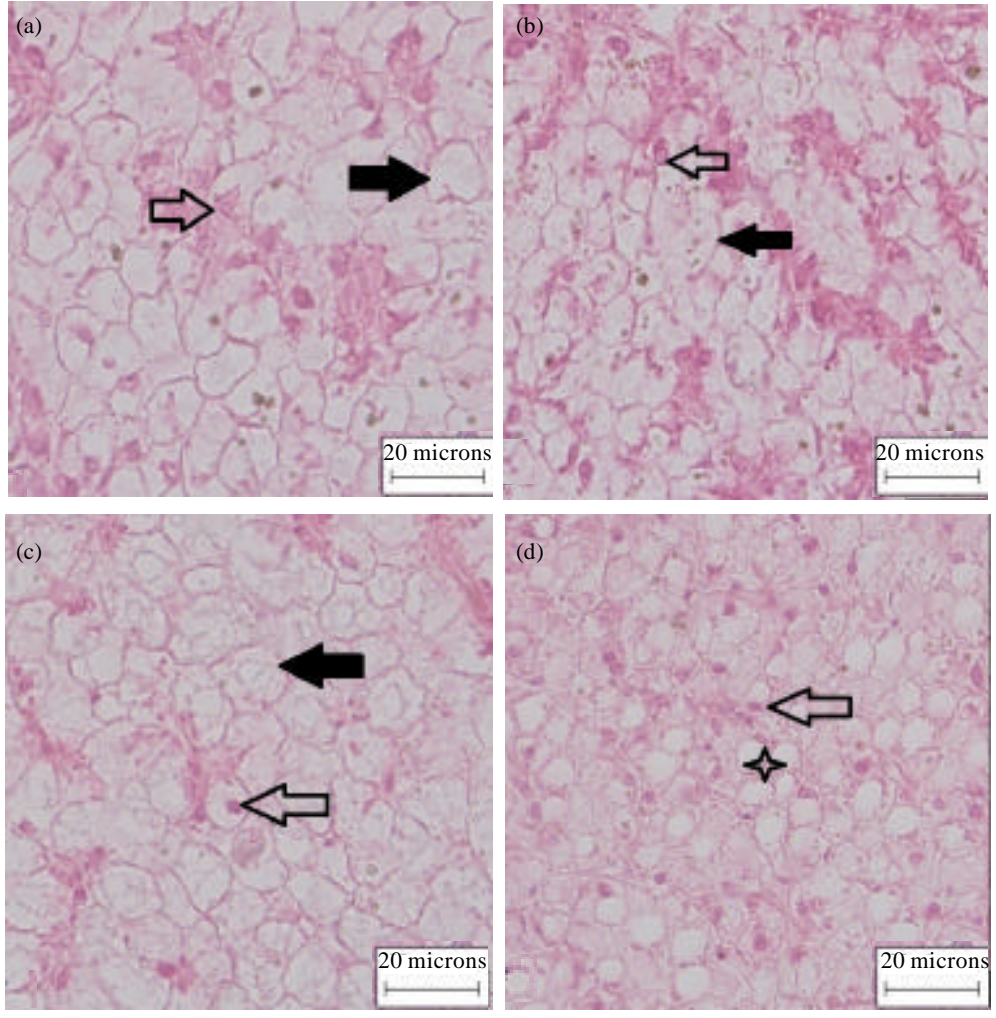

Fig. 6(a-d): Liver microscopic structure after three weeks of overfeeding (a, b, c and d) Large hypertrophic hepatocytes (solid arrows) with nuclei dislocated to cell periphery (arrows) and lipid vacuoles (four point star). (H and E; X400; Scale bars: $20 \mu \mathrm{m}$ )

Hepatocytes from both overfeeding groups were structurally different from the non-overfed groups. Very large sized hepatocytes with nuclei dislocated to the cells border (Fig. 6a, b and c) were observed in overfed groups from the third week onwards. 

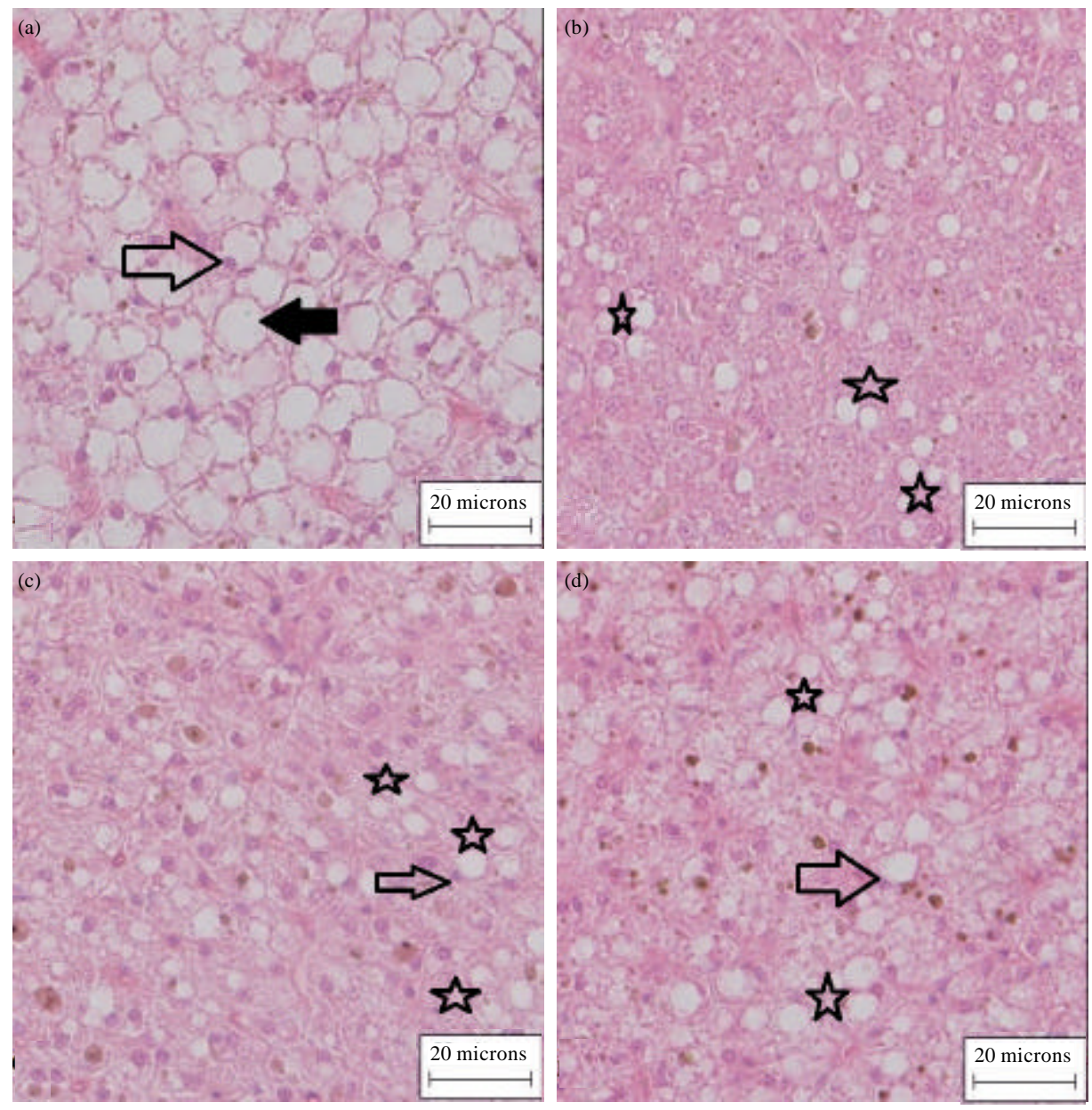

Fig. 7(a-d): Liver microscopic structure after five weeks of overfeeding. (a) Large hypertrophic hepatocytes with dislocated nuclei (arrow) and lipid vacuoles (solid arrow) and (b, c and d) Shrunken hep atocytes with inconspicuous dislocated nuclei (arrow) and circular lipid vacuoles (five point stars) ( $\mathrm{H}$ and E; X400; Scale bars: $20 \mu \mathrm{m}$ )

Moreover in the overfed group, circular lipid vacuoles were also present together with large sized hepatocytes (Fig. 6d) in some livers during the third week. Whereas during the fifth week, highly decreased hepatocyte volume and severe hepatocyte vacuolization (Fig. 7a, b, c and d) were found. Accumulation of lipid droplets in hepatocytes was inferred from the appearance of vacuoles as round, single or coalescing droplets after hematoxylin and eosin staining (Takashima and Hibiya, 1995).

HSI and HHI: The hepatosomatic index of overfed fish in the third week was significantly $(p<0.05)$ higher than of the control group (Table 2). The hepatosomatic index for fish which were overfed for five weeks was significantly higher than the control, but lower than in the overfeeding group in week three.

The hepatohypertrophic indices of overfed fish after three and five weeks were significantly higher than in the control group (Table 3). However, the mean hepatohypertrophic index in the overfed group after the fifth week was significantly $(\mathrm{p}<0.05)$ lower than in the third week. 
J. Fish. Aquat. Sci., 9 (2): 63-74, 2014

Table 3: Mean $\pm \mathrm{SE}$ of hepatohypertrophic index $(\mathrm{p}<0.05$ ); means with different letters are significantly different

\begin{tabular}{lcc}
\hline Feeding group & N & Hepatohypertrophic index (HHI) \\
\hline Control week zero & 12 & $1.02 \pm 0.06^{c}$ \\
Control week three & 9 & $1.12 \pm 0.04^{\mathrm{c}}$ \\
Treatment week three & 9 & $1.99 \pm 0.27^{\mathrm{a}}$ \\
Control week five & 17 & $0.96 \pm 0.03^{\mathrm{c}}$ \\
Treatment week five & 16 & $1.58 \pm 0.14^{\mathrm{b}}$ \\
\hline
\end{tabular}

\section{DISCUSSION}

Pathologically, the functional disturbances produced by injury to cells are often mirrored by structural changes, just as, in turn, structural damage may be followed by loss or alteration of some normal function (Woolf, 2000). As a central metabolic organ with main function as digestive gland, it is clear that morphological and structural changes in fish liver affect its normal functioning.

It was indicated that hepatocytes of milkfish fry can alter their structure according to the feeding regime to an extent hitherto unknown among teleost fishes (Storch et al., 1983). On a study which was done to establish a Zebrafish model for diet induced obesity, hepatosteatosis was found as a result of eight weeks of overfeeding with Artemia (Oka et al., 2010).

Stressors to the liver are known to disrupt the microcirculation of the hepatic parenchyma. In the present study, overfeeding in the first few weeks might have increased the transport of nutrients, mainly free fatty acids, to liver cells from stomach and intestine via hepatic portal vein. Increased nutrient inflow means increased work load for these cells and this situation puts them on a hyperfunctional condition. It is known that free fatty acids from ingested food are normally transported into hep atocytes, where they are esterified to triglycerides, converted into cholesterol or phospholipids, or oxidized to ketone bodies (Kumar et al., 2009).

Hence, esterifying as well as oxidizing the excess inflow of fatty acids and other nutrients probably increased the work load of the hepatocytes. Hypertrophy is a cellular response which occurs during increased functional demand (Takashima and Hibiya, 1995; Kumar et al., 2007). Therefore, the hypertrophy observed in the present study after three weeks of overfeeding might have occurred as a cellular stress response to increased inflow of nutrients to liver cells (Fontagne et al., 1998) and increased workload.

Swelling of hepatocytes as a result of hypertrophy might have caused narrowing of sinusoids and disse spaces. Disse space is peri-sinusoidal space located between hepatocytes and sinusoids. Hepatocytes get blood and oxygen via sinusoids from hepatic portal vein and artery. The blood reaches to hep atocytes from sinusoids through disse spaces. Narrowing of sinusoids and disse spaces as a result of swelling hep atocytes likely caused obstruction of blood and oxygen flow to hep atocytes (Hwang, 2011). Increased nutrient inflow and obstructed blood as well as oxygen supply could lower the metabolizing capacity of hepatocytes. This probably led to deposition of lipid in hepatocytes and fatty degeneration.

Eventually hepatocytes of the overfed fish become in a hypofunctional condition. Decreased workload and low blood supply are known to cause atrophy to cells (Takashima and Hibiya, 1995; Kumar et al., 2007). For this reason, the lipid vacuolation and atrophy observed in this study after five weeks of overfeeding might have happened because of poor metabolizing capacity of hepatocytes as a result of obstruction of sinusoidal blood flow. 


\section{CONCLUSION}

Overfeeding of Nile Tilapia, with commercial feed caused morphological alterations to the liver. Liver histomorphological changes observed in the present study are believed to disrupt the normal functioning of the liver. Taking into account the role of liver in the general physiology of fishes, it is likely that such an affected liver lowers the fish's resistance to disease outbreaks.

It is apparent that aquaculture profitability highly depends on the fish's health status. Therefore, overfeeding may indirectly lower fruitfulness of aquaculture industry by affecting healthiness of the fish.

Comparisons of histological as well as immunological assays are recommended to be done to clearly show how the healthiness of the fish gets affected by overfeeding.

\section{ACKNOWLEDGMENTS}

It is our pleasure to express our gratefulness to Korea International Cooperation Agency (KOICA) and Pukyong National University which helped us to carry out this research. We would also like to say thank you to Mr. Paulos Getachew and Professor Chang Young Jin for their valuable comments on the draft manuscript. Our deep gratitude goes as well to Kim Bo Sung, Najib, Seon Ju and Semyung.

\section{REFERENCES}

Abdel-Warith, A.A., E.M. Younis, N.A. Al-Asgah and O.M. Wahbi, 2011. Effect of zinc toxicity on liver histology of Nile Tilapia, Oreochromis niloticus. Sci. Res. Essays, 6: 3760-3769.

Asdari, R., M. Aliyu-Paiko and R. Hashim, 2011. Effects of different dietary lipid sources in the diet for Pangasius nasutus (Bleeker, 1863) juveniles on growth performance, feed efficiency, body indices and muscle and liver fatty acid compositions. Aquacult. Nutr., 17: 883-891.

Boyd, C.E., 2004. Farm-level issues in aquaculture certification: Tilapia. Report Commissioned by WWF-US, Auburn University, Alabama, pp: 1-29.

Caballero, M.J., G. Lopez-Calero, J. Socorro, F.J. Roo, M.S. Izquierdo and A.J. Fernandez, 1999. Combined effect of lipid level and fish meal quality on liver histology of gilthead seabream (Sparus aurata). Aquaculture, 179: 277-290.

Cataldi, E., S. Cataudella, G. Monaco, A. Rossi and L. Tancioni, 1987. A study of the histology and morphology of the digestive tract of the sea-bream, Sparus aurata. J. Fish Biol., 30: 135-145.

Coyle, S.D., R.M. Durborow and J.H. Tidwell, 2004. Anesthetics in Aquaculture. SRAC Publication, Texas, pp: 6.

Duncan, D.B., 1955. Multiple range and multiple F tests. Biometrics, 11: 1-42.

El-Saidy, D.M.S.D. and M.M.A. Gaber, 2005. Effect of dietary protein levels and feeding rates on growth performance, production traits and body composition of Nile Tilapia, Oreochromis niloticus (L.) cultured in concrete tanks. Aquac. Res., 36: 163-171.

El-Sayed, A.M., 2006. Tilapia Culture. 1st Edn., CABI Publishing, UK., ISBN: 9781845930165 , Pages: 304.

Fahprathanchai, P., K. Saenphet, K. Meng-Umphan, Y. Peerapornpisal, S. Aritajat, S. Saenphet and P. Sudwan, 2007. Histopathological and hematological evaluation of Nile Tilapia (Oreochromis niloticus) exposed to a toxic Cyanobacterium (Microcystis aeruginosa). Southeast Asian J. Trop. Med. Public Health, 38: 245-248. 
Ferguson, H.W., 2006. Systemic Pathology of Fish: A Text and Atlas of Normal Tissues in Teleosts and their Responses in Diseases. 2nd Edn., Scotian Press, United Kingdom, London, ISBN-13: 9780955303708, Pages: 367.

Fontagne, S., I. Geurden, A.M. Escaffre and P. Bergot, 1998. Histological changes induced by dietary phospholipids in intestine and liver of common carp (Cyprinus carpio L.) larvae. Aquaculture, 161: 213-223.

Gao, Y. and J.Y. Lee, 2012. Compensatory responses of Nile Tilapia Oreochromis niloticus under different feed-deprivation regimes. Fish. Aquat. Sci., 15: 305-311.

Genten, F., E. Terwinghe and A. Danguy, 2009. Atlas of Fish Histology. BIOS Scientific Publishers Limited, India, ISBN-13: 9781578085446, Pages: 215.

Hadi, A.A. and S.F. Alwan, 2012. Histopathological changes in gills, liver and kidney of fresh water fish, Tilapia zillii, exposed to aluminum. Int. J. Pharm. Life Sci., 3: 2071-2081.

Htun-Han, M., 1978. The reproductive biology of the dab Limanda limanda (L.) in the North Sea; gonadosomatic Index; Hepatosomatic Index and condition factor. J. Fish Biol., 13: 369-378.

Hwang, S., 2011. Microcirculation of the Liver. In: Venous Embolization of the Liver, Madoff, D.C., M. Makuuchi, M. Nagino and J.N. Vauthey (Eds.). Springer, London, pp: 9-13.

Jalaludeen, M.D., M. Arunachalam, M. Raja, S. Nandagopal, S.A. Bhat, S. Sundar and D. Palanimuthu, 2012. Histopathology of the gill, liver and kidney tissues of the freshwater fish, Tilapia mossambica exposed to cadmium sulphate. Int. J. Adv. Biol. Res., 2: 572-578.

Jobling, M., 2012. R.J. Roberts (Ed.): Fish pathology. Aquac. Inter., 20: 811-812.

Kumar, V., A.K. Abbas, N. Fausto and R.N. Mitchell, 2007. Robbins Basic Pathology. 8th Edn., Saunders Elsevier, UK., pp: 810-811.

Kumar, V., A.K. Abbas, N. Fausto and J.C. Aster, 2009. Robbins and Cotran Pathologic Basis of Disease. 8th Edn., Saunders Elsevier, Philadeldhia, PA., ISBN-13: 9781416031215.

Lee, M.K., 2008. Pathological studies on green liver syndrome in farmed grey mullet, Mugli cephalus. Ph.D. Thesis, Pukyong National University.

Masser, M.P., J. Rakocy and T.M. Losordo, 1992. Recirculating aquaculture tank production systems: Management of recirculating systems. United States: Southern Regional Aquaculture Center, SRAC Publication No. 452, pp: 12. http://aqua.ucdavis.edu/DatabaseRoot/pdf/ 452RFS.PDF.

Mohanty, R.K., 2001. Feeding management and waste production in semi-intensive farming of penaeus monodon (Fab.) at different stocking densities. Aquacult. Int., 9: 345-355.

Oka, T., Y. Nishimura, L. Zang, M. Hirano and Y. Shimada et al., 2010. Diet-induced obesity in zebrafish shares common pathophysiological pathways with mammalian obesity. BMC Physiol., 10.1186/1472-6793-10-21

Oluwatoyin, A.S., 2011. Histopathology of Nile Tilapia (Oreochromis niloticus) juveniles exposed to aqueous and ethanolic extracts of Ipomoea aquatica leaf. Int. J. Fish. Aquacult., 3: 244-257.

Phillips, Jr. A.M. and H.A. Podoliak, 1957. The nutrition of trout: III. Fats and minerals. Prog. Fish-Culturist, 19: 68-75.

Raskovic, B., M. Stankovic, Z. Markovic and V. Poleksic, 2011. Histological methods in the assessment of different feed effects on liver and intestine of fish. J. Agric. Sci., 56: 87-100.

Riche, M., D.I. Haley, M. Oetker, S. Garbrecht and D.L. Garling, 2004. Effect of feeding frequency on gastric evacuation and the return of appetite in Tilapia, Oreochromis niloticus (L.). Aquaculture, 234: 657-673. 
Storch, V., W. Stahlin and J.V. Juario, 1983. Effect of different diets on the ultrastructure of hepatocytes of Chanos chanos fry (Chanidae: Teleostei): An electron microscopic and morphometric analysis. Mar. Biol., 74: 101-104.

Takashima, F. and T. Hibiya, 1995. An Atlas of Fish Histology: Normal and Pathological Features. 2nd Edn., Kodansha Ltd., Tokyo.

Verreth, J., J. Coppoolse and H. Segner, 1994. The effect of low HUFA- and high HUFA-enriched Artemia, fed at different feeding levels, on growth, survival, tissue fatty acids and liver histology of Clarias gariepinus larvae. Aquaculture, 126: 137-150.

Vicentini, C.A., I.B. Franceschini-Vicentini, M.T.S. Bombonato, B. Bertolucci, S.G. Lima and A.S. Santos, 2005. Morphological study of the liver in the teleost Oreochromis niloticus. Int. J. Morphol., 23: 211-216.

Woolf, N., 2000. Cell, Tissue and Disease: The Basis of Pathology. 3rd Edn., Saunders WB Company, Philadelphia, PA., ISBN-13: 978-0702024788, Pages: 594.

Xu, W., W. Liu, X. Shao, G. Jiang and X. Li, 2012. Effect of trichlorfon on hepatic lipid accumulation in crucian carp Carassius auratus gibelio. J. Aquat. Anim. Health, 24: 185-194. 